Article

\title{
The Future of the Food System: Cases Involving the Private Sector in South Africa
}

\section{Laura M. Pereira}

Sustainability Science Program, Kennedy School of Government, Harvard University, 79 John

F. Kennedy Street, Box 81, Cambridge, MA 02138, USA; E-Mail: laura_pereira@hks.harvard.edu; Tel.: +1-617-496-0426

Received: 3 December 2012; in revised form: 7 March 2013 / Accepted: 8 March 2013 /

Published: 19 March 2013

\begin{abstract}
The food system is facing unprecedented pressure from environmental change exacerbated by the expansion of agri-food corporations that are consolidating their power in the global food chain. Although Africa missed the Green Revolution and the wave of supermarket expansion that hit the West and then spread to Asia and Latin America, this is unlikely to continue. With a large proportion of sub-Saharan African countries' GDP still heavily reliant on agriculture, global trends in agri-food business are having an increasing impact on African countries. South Africa, a leader in agribusiness on the continent, has a well-established agri-food sector that is facing increasing pressure from various social and environmental sources. This paper uses interview data with corporate executives from South African food businesses to explore how they are adapting to the dual pressures of environmental change and globalisation. It shows that companies now have to adapt to macro-trends both within and outside the formal food sector and how this in turn has repercussions for building sustainable farming systems-both small and large-scale. It concludes with the recognition that building a sustainable food system is a complex process involving a diversity of actors, however changes are already being seen. Businesses have strategically recognised the need to align the economic bottom line with social and environmental factors, but real sustainability will only happen when all stakeholders are included in food governance.
\end{abstract}

Keywords: food system; food value chains; global environmental change; socio-ecological systems; food security; governance; corporate strategy 


\section{Introduction}

The global food system is undergoing transformation from a combination of factors ranging from the significant impacts of global environmental change (GEC) to the rapid expansion of transnational agribusiness. As such, this combination of social and environmental drivers of change results in the food system being a socio-ecological system facing "double exposure." "Double exposure" is understood here as the combined effects of globalisation and global environmental change (GEC) that act individually, synergistically and even antagonistically to create uneven outcomes or "winners" and "losers" [1-3]. These changes make it increasingly difficult for the three outcomes of a well-functioning food system to be achieved: food security, social welfare and environmental welfare [4]. Climate change in particular has been identified as a major environmental threat to food systems providing food security, especially from its disproportionate impact on developing country agriculture [5] and it is continuously referred to in this paper.

The broad question discussed in this paper is how South African food retailers are responding to trends in the global food system as well as to local processes of socio-economic and environmental change. In essence, this refers to how the current food system is at a crossroad where it is becoming increasingly important for corporate strategy to grapple with the challenge of sustainability, here defined as the goal of balancing the three pillars of social, economic and environmental wellbeing both intra- and inter-generationally. With the recent focus on meeting food security needs under global environmental change, food businesses are precipitating a shift in their business model towards more sustainable practices [6]. At the same time they are being faced with changing consumer preferences: in the West "alternative food networks" are becoming increasingly more fashionable [7] whilst in the developing world, increasing economic prosperity has resulted in the expansion of supermarkets and consumer demand for higher-end food products [8]. In light of this, the two main arguments put forward in this paper are that, in order for development and food security needs to be met, (1) there needs to be a sustainability transformation along the food chain whereby the private sector engages with small-scale farmers by creating markets that these farmers can sell into; and (2) this requires innovative thinking around product development, capacity development and customer awareness that will enable this transformation to occur with positive financial gains on all sides. This paper therefore sets the stage for a greater discussion on how to navigate this transformation in the broad context of sub-Saharan Africa and South Africa in particular.

This paper begins with discussing the implications of the broader transformations in the private sphere of the food system on food security outcomes in sub-Saharan Africa. Within the context of sustainability initiatives and responses to climate change more specifically, it then uses case study material from South Africa to illustrate how the private sector is trying to come to terms with the aforementioned complex processes of change and their interactions in their business strategy. Since supermarkets and by association food processing companies are at the forefront of these international trends, the focus of the argument lies with their response to these global shifts. The paper concludes with a discussion on the importance of understanding the processes of self-organisation and re-orientation taking place in the private sector in order to construct an enabling environment for "adaptive food governance" that can start to meet food security objectives [9]. 
The theoretical analysis of the empirical data collected from interviews is based on complex adaptive systems (CAS) theory, which is described in the next section.

\section{Theoretical Foundations and Methods}

Socio-ecological systems (SES) are the complex combination of social (e.g., economic, political, legal, etc.) and ecological systems. This complexity is created not just through interactions of interdependent variables across scales and levels [10,11], but also through multiple feedbacks and thresholds present in the system at large. Since most policy is not designed for the surprises inherent in these types of systems, these unanticipated feedbacks create challenges for governance and policy [12]. Ericksen [4] argues that the food system is a prime example of an SES; it is a complex interaction of actors and their activities with food security as its "complex outcome" [13]. Furthermore, it exhibits the non-linear feedback loops characteristic of complex socio-ecological systems: for example, unanticipated impacts on ecosystem stocks and services can result from food system activities (like production and distribution) and social feedbacks include people's responses to shocks by drawing down their assets beyond critical thresholds and falling into the poverty trap [13].

It is therefore fair to argue that the food system, as a socio-ecological system, is also a complex adaptive system (CAS). Characteristics of complex adaptive systems include: non-linearity, sensitivity to initial conditions, self-organisation and emergence. (See Pereira [14]). CAS theory has become an increasingly important area of interdisciplinary research and leading groups working on it are the Santa Fe institute and the Resilience Alliance. However, much of this work remains in the realm of the theoretical, mathematical or applied to ecosystems at the local level. This could be attributed to the increased plurality of factors operating at higher levels of organisation and therefore a loss in ability to attribute causation in any particular direction. It could also be due to the difficulty of attributing characteristics to social systems that emerge from the system itself rather than from the mindful action of the human actors within the system. For example, one area where CAS theory has been strongly advocated, but where its plurality and lack of coherence has proved problematic, is in the study of social systems like organisations. Results of such studies have shown that during their development, organisations tend towards equilibrium and stability rather than novelty or dynamism and that power differentials and other psycho-sociological factors are more relevant than those relating to adaptive behaviour, self-organisation or emergence [15]. As social organisations, the food businesses that provide the case studies for this paper are used to illustrate that practically this "tendency towards equilibrium" can be overcome when an organisation needs to respond to complex and uncertain future environments or "turbulence." Climate change and its impacts on the food system provide one such uncertain future scenario and issues of development do too. Furthermore, this paper emphasises that a transition to sustainability is an emergent property of the system in which the organisation finds itself; it can be facilitated by management processes, but is ultimately a complex articulation of the actors and their activities.

When dealing with complex systems, it is necessary to employ specific methodologies that are sensitive to the characteristics of these systems: that they are inherently unpredictable, emergent and do not tend towards equilibrium [16]. This influences the type of data that is needed in order fill in 
the gaps of understanding that nonlinearity creates. Qualitative data (e.g., participant observation or key informant interviews) is useful in identifying the emergent properties of a system as experienced by the actors within. This is particularly necessary in complex systems like the food system, which "exhibit turbulent behaviour, extreme sensitivity to initial conditions and branching behaviours at critical thresholds" (Wood et al. [17], p. 49).

Thus, a qualitative methodological approach was employed in this paper with key informant interviews forming the basis of the data that was collected, followed by e-mail correspondence and reference to company annual reports. The interview approach was left deliberately open-ended and the scope of the interviews was broadly defined, although a list of questions was sent to interviewees beforehand so that they were aware of the general thrust of the discussion. By broadly defining the problem, it was left open to the discussants to raise what they thought were the most relevant points-thereby not pre-emptively reducing the focus of the study and risking "doing violence to precisely the complexity and diversity" of the system (Chambers and Conway [18], p. 81).

In order to understand the various incentives and constraints around corporate decision-making, the paper employs evidence from qualitative data gathered in preliminary semi-structured interviews with key informants from the private sector in South Africa. Five semi-structured interviews were conducted with corporate executives at four South African food businesses; one food processor-Tiger Brands, two food retailers-Pick 'n Pay and Woolworths Ltd., and a carbon neutral wine estate, Backsberg Wine Estate. These companies were chosen firstly because they had demonstrated a commitment of some sort towards social and environmental responsibility and had executives that were willing to be interviewed. The interview with Tiger Brands' head of corporate sustainability took place in Johannesburg in September 2009 with subsequent e-mail correspondence with the managing executive of Jungle and King foods at Tiger Brands during March 2010. The interview with the head of sustainability at Woolworths Ltd. took place in August 2010 in Cape Town and the two Pick 'n Pay interviews took place in December 2009 (with the head of fresh produce) and January 2010 (with the senior manager of sustainable development) in Johannesburg and Cape Town respectively. The interview with the CEO of Backsberg wine estate took place in Paarl in January 2010.

The main objective of these interviews was to conduct a preliminary study to identify the constraints and enablers for building a sustainable food system from the perspective of the private sector, which had not been done previously. Each interview was approximately an hour long and they were conducted so as to allow the interviewees to freely discuss issues of adaptation as well as the challenges and constraints on implementing requisite changes. The interviews were taped and then later transcribed. The qualitative data that resulted often referred to issues of uncertainty and complexity that the businesses were facing in this sector, justifying the use of complex systems theory to interpret the data. After a thorough analysis of the material, three key themes were identified from the interviews: innovation, customer awareness and procurement strategy.

\section{The Developing World: Food Consumption in Africa}

How and what we eat is largely determined by the contextual socio-economic, political and cultural fabric of the food system in which we find ourselves and processes of change cannot be divorced from 
these contextual factors. The role that private sector actors have played in shaping this context has become highly significant over the second half of the last century, particularly given the consolidation of power that the agri-food sector has undergone internationally (see von Braun and Diaz-Bonilla [19], Patel [20]). However, these actors and change processes have not occurred uniformly across temporal and spatial scales. Rather it is necessary to differentiate between developed and developing country economies. The 1960s Green Revolution transformed the food system through a phenomenal increase in agricultural yields [21]. The same transformative power is evident in the current wave of western consumerism that has direct implications on how and what is grown around the world [22]. Although the Green Revolution largely skipped Africa, the same cannot be said for the contemporary trend of global food sourcing; global trends in expanding agri-food business as well as the consumer-driven "alternative food" backlash are having a substantial impact on farming systems everywhere [22]. These "alternatives" include the organic, local and slow food movements and the more mainstreamed or commercialised processes of food labelling and certification. In essence, the evolution of "alternative food networks" has attempted to bridge the ever-increasing divide between food production and consumption [7].) In fact, the reform of the European Common Agricultural Policy (CAP) has encouraged some scholars to consider the "alternative food paradigm as a new form of rural development, offering opportunities for diversified rural livelihoods" [7]. Questions facing African policy-makers include whether something similar to the CAP would work in the African context and then whether African farmers should be looking to tap into the globalised agro-industrial complex of supermarket supply chains, to create these markets at home, to provide (and mainstream) the "fair trade"/"organic"/"traditional" alternative or all of the above.

Agriculture still forms an important part of African economies accounting for 70 percent of the labour force and contributing over 25 percent to GDP [23]. Despite the importance of agriculture in these economies, African agriculture is still viewed as local, subsistence production-rain-fed with low inputs. It is therefore difficult for many of these producers to meet the stringent requirements for export or even to supply local supermarkets, however, there is increasing evidence of some successful farmers tapping into this new market [24]. It is therefore necessary to understand the nuances and variation of rural African communities and in particular how they face increasing pressure from urbanisation and deagrarianisation [25,26]. For those farming communities that remain in farming, they face increasing environmental variability as well as economic volatility (both in input prices and in commodity prices) resulting in compromised subsistence agriculture [27]. Since they often can no longer meet household food requirements by growing food, these rural households have become reliant on buying food from the private sector in order to meet their food security needs - this was largely the reason why the dramatic food price increases in 2007/2008 caused such a food security crisis [28].

Indeed, in southern Africa most rural households are increasingly net food buyers and livelihood strategies are reflecting this through diversification out of agriculture, urbanisation and migration [25]. This leaves a gap of firstly where food is being produced, and secondly, from where households are buying their food. In terms of the latter, this role is being taken on by local entrepreneurs and in some instances, through the expansion of supermarkets [26]. As local producers face pressures from an unpredictable climate, this trend will continue to place increasing pressure on agribusiness to meet the food requirements of communities through their extensive supply base [14]. The implications are how 
to ensure that the expansion of supermarkets occurs in a way that builds resilience in rural communities rather than increasing people's vulnerability to environmental and socio-economic stresses. It has been argued that further entrenching supermarkets as the main source of food for communities reinforces their already dominant power in the world's food system, but that a consequence of this power is that their absence in certain areas can also reinforce these inequalities (See Larson [29], Patel [20], Goodman [7]). However, here I argue that since they are already important actors in the configuration of the food system, any response that does not include supermarkets is naïve and does not take into account the inter-dependencies of a complex system with emergent properties. However, the private sector-and supermarkets in particular-similarly needs to adapt to the changing circumstances of the global food system and in particular to issues of equity. Their new role would necessitate not only making food available, but ensuring that it is affordable (that people have sufficient means to buy it), which means incorporating the expansion of the agri-food industry into the discussion on rural livelihoods and food security. Thus there is a dual element to the discussion of the role of agribusiness in African food systems. The first is from the production perspective and how demand from the West is affecting what is being grown in African agricultural systems as well as how it is being grown and who is growing it. The second is through the expansion of these markets into African countries, creating local demand for supermarket-style Western consumerism that needs to be met-preferably by local producers.

This empirical section of this paper focuses mainly on the latter's importance in defining African food systems, although the role of demand in the West is equally important and parallels can be drawn between the two processes. Food consumption in the developing world has undergone terrific transformation since the 1980s with the expansion of supermarkets into Asia and Latin America [8]. Although this revolution largely missed Africa, this is unlikely to continue to be the case and indeed there is evidence of a food consumer revolution happening in many African urban centres [30]. Indeed, figures for rural and urban areas in South Africa confirm this trend and show that all households purchase some, if not most, of their food [26,31]. If sub-Saharan Africa (and the rest of the developing world) is jumping on the food consumerist bandwagon, is it inevitable that it follows the same trends as in the West? It seems that for those countries whose agricultural systems were transformed by the Green Revolution, they are already on the conventional consumerist development path-from industrialisation and mechanisation to supermarket expansion, thereby increasing the disconnection of consumption from production (and the rural areas where production takes place) [22]. These processes are being seen in the developing world [32,33], but they are having some effects that did not occur in the West.

Whilst rural economies in the West are kept productive through farm subsidies (e.g., the CAP), this is not the case for developing countries that are made to abide by stringent regulations on liberalisation enforced through structural adjustment programmes or WTO regulations for tropical crops with only a few Least Developed Countries (LDCs) gaining preferential access to European markets. As a result, African farming systems cannot withstand urbanisation and deagrarianisation pressure because their farming systems have been neglected for so long [28]. Farming policy must seek to address and reverse these trends that leave rural areas unproductive and an income sink rather than a source. The private sector also has a definite role to play here too, as will be discussed below.

At the same time, African agricultural markets are integrally linked to global demand trends, which have recently begun to place an emphasis on how an agricultural product is produced (i.e., its social 
and environmental or "sustainability" impact) (See Pereira [22]). The creation of a market where knowledge about the production process can translate into a price premium has important implications for governance in a system where trust becomes an important element. Pereira [22] proposes three forms of governance that provide the context of how farming systems function and in each case there are a diverse array of actors involved.

(1) Consumer-led governance is driven through the creation of a market for knowledge about how products are produced and the mechanisms it employs to ensure trust in these products are certification and labelling schemes. It relies on customers wanting to ensure a certain ethical standard in the production of their food.

(2) Third party or retailer-led standards are arguably also formulated in order to meet customer requirements, but are designed by retailers in isolation and dictated to farmers rather than including them in the process. International standards from the WTO can be included under this type of governance as standards are set by a third party that is neither involved in producing the product nor consuming it.

(3) A mutual process between producers and buyers that addresses the needs of both-the key is to build on meeting mutual needs and thus creating equal benefits: retailers want produce that they can sell to their customers who want good healthy food, and farmers want a market; the real contention lies in how the specifics are negotiated. If the negotiation is conducted in the spirit of partnership and mutual understanding rather than through dictated terms, this is more likely to meet the requirements of all parties better [34]. The key is to make the result as mutually beneficial to all parties as possible.

Using South Africa as a case study, Section 4 discusses how the private sector is mobilising to meet some of these sustainability challenges because it makes business sense for them to do so. The focus of the next section is on how processes of self-organisation currently underway in the South African food system have the potential to move the system towards the third type of governance laid out above as a response to various socio-environmental pressures. Although not definitive, the empirical evidence presented shows that enabling spaces do exist where the needs of multiple stakeholders can start to be negotiated. The challenge, especially for public policy, is to find these spaces and to nurture them in order to provide incentives for more powerful actors to engage in "adaptive governance" that is ultimately about building a more sustainable food system.

\section{South Africa as a Case Study}

The Latin American/Asian food retail story that started in the mid 1990s, which featured waves of foreign direct investment by global multinationals such as Ahold, Walmart, and Carrefour, has recently begun in Africa and there are pockets of supermarkets growing in southern and eastern Africa [30,35]. According to a study by Reardon et al. [8], post-apartheid South Africa has become the African front-runner with roughly a 55 percent share of supermarkets in overall food retail. South African retailing is composed of two different sectors: the informal sector comprising hawkers, small stands and spaza shops, and the formal sector consisting of large format hyper- and supermarkets, smaller superettes and then "non-major" stores like convenience stores, urban counter and self-serve stores [30]. 
The progression of the formal sector stores is similar to the experience of retailers in Argentina and Costa Rica where the format changed from supermarkets to hypermarkets and then convenience stores. Geographically, retailers moved from high-income areas and in major cities to rural towns and townships where they began to cater to middle and lower income strata [30].

South Africa's growth over the past decade has largely benefitted the upper income group with 40 percent of the country's income going to 10 percent of the population [36]. Agriculture does not make as significant a contribution to South Africa's GDP as it does in other African countries, amounting to 2.3 percent in 2010 (from StatsSA). From the early 2000s, the stronger Rand resulted in lower profitability from exports and the agriculture sector actually shed workers [36]. Thus, the agricultural trends from the apartheid era continue: a divided agricultural economy with large-scale commercial producers on one side supplying supermarkets and processors and poor small-scale producing for subsistence [14]. With very high levels of poverty, especially in rural areas, the South African government's New Growth Path strategy highlights the need for rural development with a specific focus on smallholder job creation [36]. These wider trends are affecting agricultural choices at the local level and need to be harnessed to improve the adaptive capacity of rural households to the uncertain future impacts of stressors like climate change. As will be shown below, the private sector, and retailers in particular, are increasingly becoming engaged in this process.

South Africa's two top retailers, Pick 'n Pay (est. 1967) and Shoprite Checkers (est. 1979), have approximately 40 percent of the turnover in the sector each and have also invested heavily in other African countries as well as India, Australia and the Philippines [8]. As Johannesburg Stock Exchange (JSE) listed companies, they ranked 127th and 129th respectively in the 2009 Stores global survey, making them relatively important players, especially in southern Africa [37]. Woolworths and Spar complete the formal retail sector with Massmart (which has now been taken over by Walmart) and Metcash being the country's two main wholesalers [38]. With growing urbanisation and a burgeoning middle class, food retailers play a significant role in the country and are vital actors in the agri-food chain for innovation around development issues [38] and potentially climate change adaptation too [14]. That being said, this "rapid rise of supermarkets" has also extended into poor neighbourhoods and the new trend in the region is of "supermarkets to the poor", making them important both from a food security perspective, as well as for rural development (Weatherspoon and Reardon [30], p. 1).

Thus, South Africa provides a microcosm of the global consumerism divide as it has characteristics of both the developed and the developing world. South Africa has a well-established agrifood sector that is facing increasing pressure from various sources; including climate variability affecting production, a global drive towards "sustainability", certification and the need to support local capacity development in the agricultural sector [34]. According to Pereira [22], South African food business has a triple prerogative regarding building a more sustainable food system:

(1) To promote development and job creation in order to establish a viable customer base/ reliable farmers.

(2) To ensure that the food system is resilient to processes of global environmental and economic change (i.e., "double exposure"). 
(3) To build a successful food sector through creating and sourcing products that not only meet the needs of customers and international food safety requirements, but also are socially acceptable for an "African context" [39].

Although I do not expand on the "African critique" to Western-style liberal democratic governance (see Swilling et al. [40] for an in-depth analysis of governance in African cities), many of its criticisms reflect the problems identified in the mono-centric approach to food governance [34]. The importance of "relational capital" in a complex, fluid and inter-connected society with entrenched diversity does not map well onto the governance schema proposed by development institutions [40]. We need to only look to the failures of structural adjustment programmes (SAPs) and in particular their impact on the food system, to get a sense that there must be a wiser alternative for food governance in Africa [19]. In Africa, South African companies dominate as they play a similar role on the continent to that of multinationals globally, but they still face resistance in many African countries because their expansion is viewed as a form of neocolonialism [39]. In response to this dilemma, a key development in corporate governance in South Africa has been the establishment of the King Code on Corporate Governance. These are unique because of the distinct situation of governance in South Africa that was situated in a "highly turbulent and fluid context ...where South African companies [needed to meet] international corporate standards without neglecting their allegiance to the African continent", echoing former president Thabo Mbeki's call for "An African Renaissance" (Roussouw et al. [41], p. 301). Many of the companies, facing the tension between adhering to global standards and models of best practice and the local implementation of these ideas, have established governance mechanisms where the messier network of stakeholders and interests is taken into account [42]. Recognising and responding to this complexity and enhancing the potential for collaboration between a network of interested parties can lead to more sustainable forms of local governance for companies operating under these circumstances (see Hamann and Kapelus [42] for examples of this from the mining sector, which has been at the forefront of such governance shifts).

The next section provides the results from the semi-structured interviews and provides a brief overview of some of the trends identified from the private sector in South Africa around building sustainability in the southern African food system. Three areas where the private sector can contribute to a sustainable transition were identified: innovation, raising customer awareness and procurement policies.

\subsection{Innovation}

Food processing has become the most concentrated stage in the food value chain with relatively few processing and retailing companies compared with the number of producers and consumers at either end of the chain $[8,43]$. Concerns with supply under changing market and environmental conditions reinforce their engagement in governance, most notably from a mitigation perspective as agriculture contributes approximately 13 percent to global greenhouse gas emissions and the rest of the food supply chain even more [44]. However, the role of business does not stop with the mitigation of environmental change; in the developing world, their role in adapting to a changing environment is increasingly being recognised, despite progress being slow [45]. Product innovation is one of the key ways in which the adaptive capacity of food processors to global environmental change can be harnessed. Not only is 
this the area in which processors can respond to adaptive innovation taking place in production (e.g., crop diversification and rotation strategies, organic farming and irrigation), innovation can also increase adaptation at the consumption end of the commodity chain by providing nutritional alternatives to those vulnerable to the causes of food insecurity.

One of the greatest environmental changes projected to impact the southern African food system significantly is climate change [46-48]. Predictions for southern African agriculture under climate change in 2030 show a major decrease in staple crops like maize, but relatively little impact on "traditional crops" like sorghum [49]. The potential benefits of developing the traditional crop sector in Africa are great and more recently the private sector has come on board by creating a market for these crops in the form of lager beer (e.g., SAB Miller's sorghum-based Eagle beer in Uganda and Zambia and their cassava beer in Mozambique), malt beverages (e.g., Milo) and instant porridges (e.g., Morvite) [14,50]. Thus, food and beverage companies can contribute to sustainability through the development of products manufactured from crops that are less susceptible to climate change impacts than the staples of wheat, maize and rice.

This capacity for adaptation through innovation is exemplified by the product Morvite, which is an instant sorghum-based breakfast cereal whose development contributes to food security objectives whilst still meeting the company's commercial interests [51]. Morvite is a product of Tiger Brands, a food processing and manufacturing company for grains, beverages, and meat that is based in South Africa with a commercial interest in other African countries. Morvite was developed in the 1980s as a mid-shaft energy feed in the mining industry, which is why it is still referred to as "Phuza Amandla" or "Drink for Power." Originally it consisted of pre-cooked maize and sorghum, but in order to improve its taste, it became a ready-to-eat sorghum-only product. It is generally recognised as a nutritional food especially for children, sportsmen and mineworkers and contains 11 vitamins and 6 minerals and has now been released in six different flavours [52]. Although the rationale for creating Morvite from sorghum was not related to climate, the company recognises the fact that if sorghum is more adaptive to specific geographic regions than other crops like maize, then it would be seen as a grain of preference, especially in the case of an aversion to genetically modified crops [54]. There are certain sorghum cultivars that are preferred by farmers because their higher tannin levels make them more bird resistant. However, tannins have anti-nutritional factors affecting protein digestion and therefore the grain requires processing to remove some or all of the bran (where the tannins are located) in order for the product not to lose its nutritional value [52]. It is therefore key to ensure that the correct balance between cultivation, nutrition and processing is struck in order to get the optimum product [52].

Tiger Brands' core target group for Morvite are LSM groups 1-4 (where LSM refers to the Living Standards Measure; a marketing research tool in southern Africa, [55]) and in particular black females between the ages of 25 and 49 who have children in their care and are looking for affordable, nutritious and filling food [52]. The product is therefore perfectly situated to be a strategic product for achieving food security in southern Africa. It is already very popular in markets such as Kenya. Yet it has not become mainstream in South Africa where it is still seen as a nutrition supplement in areas where people are affected by disease and poverty or in disaster relief situations. In June 2009, it was used in a disaster relief programme for flood victims in Namibia. For the company, such product development complements a socially responsible investment programme through their "Unite Against Hunger" 
initiative, which provides food to more than 100,000 orphans and vulnerable children in collaboration with NGOs. However, any direct link to its benefits under climate change as a sorghum-based product are co-incidental, although the company recognises that a policy of product development specifically aimed at food security or climate change adaptation that could be foreseeable in the future [54].

The strategic role that such product innovation can have in building adaptive capacity in an uncertain context needs to be recognised more fully and specifically targeted (as opposed to being a by-product arising from some other pressure). Furthermore, there is a need to create consumer awareness around such innovative products so as to make them more marketable, but also as an incentive for innovation. Certification in the developed world has gone far in fostering an understanding of the value chain that links production processes with consumers [51]. However, a similar gear-change needs to be established in the developing world for food products that meet the changing needs of society, but in a way that builds adaptability and sustainability rather than compromising them. How South African retailers have recognised and are responding to this challenge is discussed in the next section

\subsection{Customer Awareness and Marketing}

In a competitive market, demand for products lies at the core of the retailers' business strategies, because they cannot exist without customers buying their products. Retailers are therefore sensitive to shifting demands and preferences amongst their customer base. Equally, they are responsible for generating much of this demand through internal competition with each other where each supermarket attempts to surpass the other with the variety and novelty of products they have available (See in particular Harvey [53] for a discussion on how supermarkets create new norms of consumption). One of the biggest trends that food retailers have identified recently is that customers increasingly demand that foods are available irrespective of the season. As a result, retailers have to invest in a variety of strategies to meet these demands, including technological innovation to slow the ripening process of fruit so that it can be kept for longer or sourcing from producers in different climatic zones:

"As retailers, we are incessantly forced by our consumers to do things out of the ordinary. So, apples grow January to March predominantly, but are available throughout the year. Why? Because consumers demanded it and other retailers did it and so everyone else had to follow. But the reality is we're doing things to the product to last. I mean you put them in controlled atmosphere chambers and you take the gas out of it so it stops ripening. Now consumers want nectarines twelve months of the year. We're sitting there saying 'Okay, we can do it, but we will have to fly it in because it has got to be imported' and they say 'No, no, carbon emissions!' So now what we're doing is we're getting involved in Africa and we're going up to Zim (sic) and we're going up to Mozambique and we're actually planting there now to try and use as little carbon emissions_-or should I rather say make it closer to us than being in Spain or those different countries." [56]

A good example is that of avocados, which can be grown successfully in South Africa, but only at certain times in the year. Outside of winter, in order to meet demand, retailers need to import avocados from northern hemisphere countries like Spain. Even though these are more expensive, some people are happy to buy them and so the business meets this demand despite the added impact from, for example, 
food miles. Woolworths has actually entered into an enterprise development programme to get avocado suppliers from other parts of the country to buy into Westphalia, their main supplier [57].

Together with this ability to innovate and change strategy in response to consumer demand, retailers also wield considerable power to influence consumer preferences and awareness around food issues. "[The] power of the retailer is through creating awareness in staff and customers, they can facilitate millions changing their lives through direct communication." [58]. This aspect of creating a customer base that is aware of sustainability issues, such as the impacts of climate change, is becoming an increasingly important aspect in retailers' strategies because in order to market a sustainability objective, you need an educated consumer base that understands the positive benefits of such a change in focus.

"I think more and more we're realising that there is an education element before people can actually understand what we are doing. So some of the stuff we talk about there is a big 'so what?' because they don't actually understand what the issue is. So I think we'd like to think that [we have one] of the most educated and demanding customer base in South Africa, but we never get or very seldom get feedback around issues of climate change and water. We get a lot of feedback on packaging, recycling, animal welfare stuff that is more product-related or close to peoples' hearts, but they're not thinking about the macro stuff. So we can tell you that climate change and water are much bigger issues than the packaging, knowing that it is still a priority, but people see the immediate thing ... a few generations ago people had family members that lived on a farm and farmed and that's fairly irrespective of race and that's really changed dramatically over the past 20/30 years ... So our new foods campaign is a lot about where food comes from. So trying to sort of create, go back to the farm and farming practices and try to understand what is required to actually produce food ... so getting that right and trying to educate people about what the key issues [are]: how food is produced and why is it a good idea to buy from us because we are trying to do something about it [is an important focus]" [57].

The key idea is to reinforce a simple message rather than (in the words of a Pick 'n Pay executive) "doomsday stuff" and to start by getting "your own house in order first," for example by distributing a sustainability newsletter to employees and to work in parallel with suppliers so that everyone is on the same page and they know what is expected of them and why [58]. It is then possible for the message to go out to customers by explaining exactly what is meant by organic or carbon footprint labelling and why there is more local sourcing of food products. The South African food retail system has not yet come full circle, as for example in the UK where it is pressure from the customers themselves that often drives the process towards sustainability or fair trade practices [51]. It is largely the retailers themselves, picking up on international trends and experiencing difficulties in procurement, that are spearheading the movement towards sustainability and taking their customers with them. Whilst at the moment the focus is very much on getting their own house in order first, there has also been a realisation of the need to bring suppliers along through a collaborative process of providing them with information as to what is expected rather than by dictating terms. This can be done through various means, for example through supplier workshops - this then builds local capacity around sustainability from the farm level.

"Education is critical and engagement along the lines of 'This is our strategy, what can you do?' (And not 'Do this!') will see the change happen slowly, but surely, and with 12,000 suppliers, this is a large change. But the change needs to be primarily in the company first and then in parallel with suppliers." [58]. 
Many of these companies have realised that "sustainability" is not just an environmental benefit, but that it has moved out of Corporate Environmental Responsibility and has become a part of normal business operations because there is a financial benefit: "the green alternative needs to be there when purchasing and if it's not chosen, the question must be why [58]." (Turning this idea on its head, Mike Barry, the head of sustainability at Marks \& Spencers, a leading UK retailer, stated that the sustainable choice should not be up to the customer, but that there should only be sustainable and ethically sourced products available on the shelf [59]). Answering the "why" lies in making customers aware about their choice of food products and the implications that their food preferences and demands make on the food system and farmers. It is clear that in order to follow international trends and implement successful sustainability initiatives, retailers need to create awareness of environmental and social issues in their customer base. This directly meets the company's own requirements, whilst simultaneously creating a knowledge platform with potential spin-offs into civil society. An environmentally and socially aware customer base extends beyond the confines of the supermarket into society at large where it has the potential to have an exponential effect on consumers making more sustainable choices. At the same time, it has impacts on the farmers who are producing for these markets, requiring them also to adapt to these new trends or alternatively, for smaller farmers to be brought into the supply chain. Food companies are starting to recognise this and have started to include the need for capacity building within their procurement policies_-not only as a response to customer demand, but also as a response to changing environmental and social conditions.

\subsection{Procurement Policies and Capacity Building}

Despite the problem of distinguishing between the effects of natural climatic variability and anthropogenic climate change, climate change has been recognised as a primary trigger for retailers to rethink procurement policies in South Africa as they have already experienced the impacts of a variable climate on procurement, particularly on stone fruit, peaches and nectarines that are major export commodities for South Africa [56]. As part of this move towards internalizing environmental variability into their procurement strategies, retailers are also responding to the dual prerogative of creating a more environmentally sustainable business model as well as achieving social objectives in an unequal society with high rates of poverty and unemployment [14]. Retailers have adopted a variety of strategies to ensure procurement under increasing uncertainty of production due to environmental as well as socio-economic factors.

\subsubsection{Spreading the Risks}

As was alluded to in the previous section, their first strategy has been to increase their number of suppliers. "What we do though is we have five suppliers on one product. So we will have one in Hoedspruit, one in Cape Town, one in Durban, one in PE (Port Elizabeth) ... all over the place and it's really about spreading the risk. So we as retailers have no other choice, we have to spread our risk and therefore ... that adds onto the cost of food because if you have one supplier with a pack-house now, you've got to have five suppliers with exactly the same pack-house so it does add, but you're not sure." [56]. 
The implications of this are two-fold. Firstly, it shows that retailers are willing to take on some of the risk of procurement in order to ensure the availability of supply (mainly to their urban centres). However, this has direct cost implications, which are then passed on to consumers who then have to pay the price for a surety of supply. On the other hand, this does not build the resilience of the farmers themselves who are affected by environmental stresses. Not only do they face the risk of losing their crop, but they face increasing competition in good years when there is an ample harvest from all suppliers. It is therefore necessary to understand the full systemic consequences of such initiatives and how to minimise the negative effects on the farmers who are most vulnerable to climate variability. Better initiatives that do not compromise farmers' livelihoods need to be negotiated within this context of retailers hedging their procurement bets. The absence of many small-scale farmers as key suppliers in the food value chain exacerbates the inequality in the food sourcing system. Woolworths has initiated a sort of "buddy-system" whereby small-scale farmers are considered as secondary suppliers attached to a primary supplier, with access to their storage and transport systems, but they fully admit that this has not had all the positive outcomes that they initially foresaw [22]. Such problems of retailers sourcing from smallholders is not unique to South Africa - contract farming is often touted as the best solution for including smallholders into the value chain, but this is also not always the best option. Successfully bringing small-scale farmers into the food value chain remains a key challenge in the South African context even with programmes for capacity building, the technical and infrastructural challenges remain unsolved.

However, despite some of these challenges, retailers are nevertheless starting to source from other African countries. Woolworths already sources from Zimbabwe and realises that as the country stabilises politically, it could be a viable option for further sourcing options. Expanding procurement from more arable parts of Africa has become even more of an option, considering some of the areas in South Africa are becoming increasingly unviable for commercial agriculture: areas like the Eastern Cape that were thought to be fairly good choice from a rainfall perspective were in a drought in 2010, resulting in a supply shortage [57]. Although year-on-year weather variability is common in southern Africa, being unable to source produce between one year and the next has substantial impact on retailer's procurement strategies in order to maintain customer loyalty (if they do not stock a product for a year or if it is at a premium price, customers will look elsewhere). However, sourcing from many countries in sub-Saharan Africa remains challenging due to the lack of basic infrastructure and data shortages [58]. In response, some retailers have therefore embarked on a drive to build capacity amongst the farmers that they work with-both smallholders and commercial farmers.

\subsubsection{Capacity Building Around Sustainability}

As Pick 'n Pay started expanding into the rest of Africa, the company decided to deal with environmental issues and social upliftment at the same time. For example, it promised the Zambian government that it would employ local people in new stores (and that family stores will be franchised to local owners) and that they will "upskill" (sic) farmers through an outgrowers scheme that aims to provide local farmers with the skills and capacity to be able meet requirements to supply these stores [56]. Recognising that a lack of skills was also a problem at home, at the same time as providing skills in 
other African countries, similar projects are being implemented domestically in South Africa. Retailers have identified a "double whammy of uncertainty" that the food system faces in the country from the combined effects of climate change and land reform, which has resulted in many farms collapsing due to a shortage of skills [56]. Retailers' strategy to expand procurement at home and into Africa therefore has further implications for capacity building up in the most environmentally sustainable practices that could help mitigate climate change as well as provide communities with the necessary skills to be productive farmers.

Together with their "Farming for the Future" initiative, Woolworths is working with farmers to become more efficient and environmentally friendly [60]. They are not only working with building the capacity of small-scale farmers (through projects like EduPlant, see Pereira et al. [60]), but also including large-scale producers too. Climate change under the guise of water stress is the predominant narrative through which these initiatives are being framed and tackled.

"A lot of our adaptation issues in SA (sic) are about water in the food supply chain. So most of our projects may not be framed as a climate change issue, but it's largely about water, which is really where all the impacts will hit. So aside from sort of looking at tracking all our suppliers around different catchment areas and biodiversity hotspots as well, knowing that we're probably going to have to shift supply out of particular areas as it becomes drier or there's quality concerns into other parts of the country or even potentially into other parts of the region, we're also working on a range of projects with particularly our fresh produce suppliers: salads, veggies, fruit. One is around wastewater practices because we've picked up that largely there is not much enforcement of legislation. We've got great water and other legislation in SA, but it's not really ever enforced. So we found that most of our suppliers aren't even compliant with legislation even though we think we've got the most sophisticated suppliers in the country. So, a lot of it has been about making sure that in the various food pack-houses there's a proper waste water management system, that they're not just discharging anything and everything back into water sources or into the fields. A lot of work [is] around trying to reduce over-irrigation, which is another big issue: looking as well as what kind of water sources they are using in particular areas. So if you're growing potatoes in the Sandveld here in the Western Cape, which is extremely dry, don't use pivot irrigation-that type of thing. So it's basic, but it's also about changing and creating awareness [57]."

\section{Discussion and Conclusions}

International trends in consumerism are affecting African agricultural systems through creating demand for products that need to meet certain specifications ranging from international safety standards to certification of the production process [22]. Added to this is the process of supermarket expansion that is creating markets for local farmers as well as offering consumers in the developing world the sort of product choices and convenient shopping experience that their counterparts in the West have enjoyed since the second half of the last century. Simultaneously, trends of environmental change and in particular climate variability are already providing shocks to the food system that require a response. These macro-trends provide the context in which the private sector has both the incentive and the capacity to develop sustainable business strategies that not only engage actors within the system, from producers 
to consumers, but also to thereby self-organise towards building a more resilient food system and in particular to help small-scale farmers, who are the most vulnerable to double exposure threats, to build their adaptive capacity.

The non-linear effects of these threats stem from the interconnectedness of the food system and are key characteristics of a CAS, best explained through the concept of "emergence". The system is more than the sum of its parts; therefore it is not helpful to understand how the system works by looking at components in isolation. Understanding systems in this way offers new governance mechanisms for building adaptive capacity. Governance in complex systems cannot address problems from a linear perspective, but needs to be embedded within a framework that understands emergent properties and the possibility of non-linear feedbacks leading to concatenated crises [61]. Appreciating these characteristics helps to frame responses; just as problems can be concatenated, so responses can have non-linear positive impacts on other parts of the system. For example, a sustainability initiative instituted to lessen environmental impacts whilst maintaining yields like Woolworths' "Farming for the Future" has had knock-on effects by increasing recycling by farmers, reducing the use of fossil fuels (i.e., mitigation) and educating customers who buy these products in store about sustainability. In South Africa local manifestations of wider change processes, such as droughts and job losses in the agriculture sector, have provided a context in which the private sector is starting to see the need to address these emergent problems in their business strategies - arguably to start thinking about transitioning towards more sustainable practices. Due to the complex nature of the food system, these responses can be amplified to produce a sea-change towards a more sustainable system, but in order for this to occur, more critical actors need to come on board [34].

Africa is facing great agricultural challenges to reinvigorate rural communities and farming systems and make them as attractive as the city as places to earn an income. There are two fundamental driving forces that will determine how this challenge is met: (1) shifting international consumer behaviour and choices around and farming systems; and (2) changing consumption patterns in Africa. Will African consumers go through the same waves of consumerism as those in the West or will it be possible to create a uniquely African consumer market that meets consumers' needs whilst being both sustainable and fair for farmers? Supermarkets and other food businesses have a key role to play in deciding the path that African food systems take. Given the findings of this paper and the key sticking points in South Africa's food system for the private sector's perspective, a proactive governmental policy strategy would entail a combined focus on re-agrarianisation (e.g., investing in infrastructure and rural capacity building) as well as providing mechanisms through which the private sector can engage cross-sectorally to create best practice for meeting sustainability challenges. The importance of engaging multiple stakeholders around the issues of sustainability and food security have already been discussed elsewhere (See Pereira and Ruysenaar [34]), but this paper emphasises the particular need of strengthening the diversity of public and private sector initiatives so that they reinforce rather than work at odds against each other.

CAS theory shows us that in order to maintain an environment that is conducive to "creative destruction" [62] requires increasing competition by providing an enabling environment to sustain a variety of actors. This is in direct contrast to focusing solely on building efficiency through streamlining processes and vertical integration into monopolies as has been happening in the global food system [22]. Ensuring that there is sufficient diversity and redundancy in the system enables the key functions of the 
system to survive the reorganisation stage and builds a resilient system. For example, from the retail perspective, relying solely on one large supplier (arguably more efficient in terms of, e.g., infrastructure investment) that then undergoes a shock (e.g., a pest outbreak) means that the whole system breaks down. However, ensuring the viability of multiple suppliers—big and small—means that the collapse in one smaller sub-system from a shock does not devastate the system. The interview data shows that some South African retailers have realised this and are implementing policies accordingly. However, ensuring the recovery of the farm that suffers a shock requires equal flexibility and redundancy in that smaller system - that is arguably where the role of public policy and the need for social safety nets starts playing a part.

Within a broader understanding of the need to adapt public policies, the examples of private sector initiatives in South Africa show a trend developing between multiple stakeholders in the food system as relationships between retailers, their customers and their suppliers are built to respond to pressure from environmental and societal issues. These are positive indications, but must be undertaken with a full understanding of the systemic impacts of policies and with multi-stakeholder and institutional support [34]. The innovation, awareness and procurement policies of retailers have a significant impact on the food system's capacity to adapt to the uncertainty of the future due to processes like climate change and thus start a transition to a more adaptive food governance system. At the same time there is a need to be cognisant of other direct and indirect impacts that they may be having. For example, instances in contract farming have demonstrated the need for a nuanced approach to handling retailer-smallholder relationships. A study by Michelson et al. [63] on supermarkets sourcing from smallholders in Nicaragua showed that farmers often made a trade-off between entering into contracts where they were assured a set range of prices for their goods versus leaving the price to be determined by the market. The domestic retailer proved to be a fairer negotiator of these contracts (offering similar prices to the traditional market) than the foreign company even though the foreign company picked up the produce direct from the farms thereby cutting out the cost of transport. A similar study by Rao and Quaim [24] in Kenya showed that when farmers had effective negotiators on their side, this helped them to enter into fair contracts with supermarkets and the authors recommended that negotiation support should become a part of institutional support programmes for farmers. Furthermore, their findings showed that increasing domestic demand for high-end products can expand the positive smallholder income effects previously restricted to high-value exports, but a potential negative consequence could be that those farmers that do not supply supermarkets (for reasons like not meeting quality standards or having sufficient production) are driven out of the market [24].

This paper was aimed at elucidating the positive role that the private sector could play in building social, financial and environmental sustainability across the value chain-from production to consumption. It does not argue that the private sector will provide all solutions to food insecurity; indeed it is the source of much that is problematic with the global food system. However, it would be foolish not to look at how to leverage its inherent power in the food system as well as its characteristics (e.g., an ability to innovate, influence over customer awareness through marketing as well as procurement strategies). By aligning these inherent business characteristics to increase adaptability within the food system to socio-environmental pressures like climate change and the need for job creation, it will be possible to reinvigorate farming systems in Africa. 
The empirical evidence indicates that the food system can be made more sustainable by leveraging the private sector's infrastructural, financial and knowledge capacity to develop productive agricultural systems (small and large-scale) in as fair and equitable a manner as possible. Retailers' needs for a certain and safe supply of produce, farmers' needs for a certain market to which they can sell their produce and customers' needs for affordable and nutritious food are theoretically not at odds. Practically, however, this is not the case in the current food system where most of the governance power lies with large corporations and international institutions (food governance types 1 and 2 above).

Although this paper provides evidence of positive steps towards "sustainability" being taken by the private sector, there is a definite role that needs to be played by other actors, such as NGOs and government around multi-stakeholder engagement and collaboration [34]. The private sector in South Africa is taking the first steps towards transitioning to sustainability, but it is a systemic challenge that can only be fully met through buy-in by other actors. Recognising the complexity of the food system and aligning the needs of its multiple actors and their activities towards sustainability is critical if food security is to be an emergent property of the system.

\section{Acknowledgements}

The author would like to thank the Future Agricultures Consortium for funding the write-up of this paper as well as to St Hilda's College, Oxford for funding the field-work in South Africa.

\section{Conflict of Interest}

The author declares no conflict of interest.

\section{References}

1. O'Brien, K.; Leichenko, R. Double exposure: Assessing the impacts of climate change within the context of economic globalization. Glob. Environ. Chang. 2000, 10, 221-232.

2. Kates, R.W. Population and consumption: What we know, what we need to know. Environment 2000, 42, 10-19.

3. Adger, W.N.; Huq, S.; Brown, K.; Conway, D.; Hulme, M. Adaptation to climate change in the developing world. Prog. Dev. Stud. 2003, 3, 179-195.

4. Ericksen, P.J. Conceptualizing food systems for global environmental change research. Glob. Environ. Chang. 2008, 18, 234-245.

5. Fischer, G.; van Velhuizen, H.; Shah, M.; Nachtergale, F.O. Global Agro-ecological Assessment for Agriculture in the 21st Century: Methodology and Results; IIASA: Laxemburg, Austria, 2002.

6. United Nations. Food Sustainability: A Guide to Private Sector Action; United Nations: New York, NY, USA, 2009. Available online: http://www.un.org/millenniumgoals/2008highlevel/ pdf/background/foodsus_guide_EMBARGOED.pdf (accessed on 28 February 2010).

7. Goodman, D. Place and Space in Alternative Food Networks: Connecting Production and Consumption. In Environment, Politics and Development Working Paper Series 21; Kings College London: London, UK, 2009. 
8. Reardon, T.; Timmer, C.P.; Berdegué, J.; Barrett, C.B. The rise of supermarkets in Africa, Asia and Latin America. Am. J. Agric. Econ. 2003, 85,1140-1146.

9. Bohle, H.; Etzold, B.; Keck, M. Resilience as agency. IHDP Updat. 2009, 2, 8-13.

10. Ramalingam, B.; Jones, H.; Reba, T.; Young, J. Exploring the Science of Complexity: Ideas and Implications for Development and Humanitarian Efforts. In Odi Working Paper; Overseas Development Institute: London, UK, 2008.

11. Thompson, J.; Scoones, I. Addressing the dynamics of agri-food systems: An emerging agenda for social science research. Environ. Sci. Policy 2009, 12, 386-397.

12. Gunderson, L. Adaptive Dancing: Interactions Between Social Resilience and Ecological Crises. In Navigating Social-ecological Systems: Building Resilience for Complexity and Change; Berkes, F., Ed.; Cambridge University Press: Cambridge, UK, 2003.

13. Ericksen, P.J.; Stewart, B.; Dixon, J.; Barling, D.; Loring, P.; Anderson, M.; Ingram, J. The Value of a Food System Approach. In Food Security and Global Environmental Change; Ingram, J., Ericksen, P., Liverman, D., Eds.; Earthscan: London, UK, 2010; pp. 25-45.

14. Pereira, L. Private sector adaptive capacity to climate change impacts in the food system: Food security implications for South Africa and Brazil. PhD thesis, University of Oxford, Oxford, UK, 2012.

15. Houchin, K.; MacLean, D. Complexity theory and strategic change: An empirically informed critique. Br. J. Manag. 2005, 16, 149-166.

16. Berkes, F.; Folke, C.; Colding, J. Navigating Social-Ecological Systems: Building Resilience for Complexity and Change; Cambridge University Press: Cambridge, UK, 2003.

17. Wood, S.; Ericksen, P.; Stewart, B.; Thornton, P.; Anderson, M. Lessons Learned from International Assessments. In Food Security and Global Environmental Change; Ingram, J., Ericksen, P., Liverman, D., Eds.; Earthscan: London, UK, 2010.

18. Chambers, R.; Conway, G. Sustainable rural livelihoods: Practical concepts for the 21st century; IDS Discussion Paper 296; Institution of Development Studies, Brighton, UK, 1991.

19. Von Braun, J.; Diaz-Bonilla, E. Globalisation of Food and Agriculture and the Poor; Oxford University Press: New Delhi, India, 2008.

20. Patel, R. Stuffed and Starved: From Farm to Fork, the Hidden Battle for the Wold Food System; Portobello Books Ltd.: London, UK, 2007.

21. Borlaug, N. The Green Revolution Revisited and The Road Ahead. In Special Anniversary Lecture; The Norwegian Nobel Institute: Oslo, Norway, 2000.

22. Pereira, L. Waves of consumerism and the future of the South African farming system. Cahiers Agr. 2013, Under review.

23. UNECA. Challenges to Agricultural Development in Africa; United Nations Economic Commission for Africa: Addis Ababa, Ethiopia, 2009.

24. Rao, E.; Quaim, M. Supermarkets, farm household income, and poverty: Insights from Kenya. World Dev. 2011, 39, 784-796.

25. Bryceson, D. The scramble in Africa: Reorienting rural livelihoods. World Dev. 2002, 30, 725-739. 
26. Pereira, L.; Cuneo, C.; Twine, W. Understanding the role of the private sector in building rural food security at the local level: A case study from the Agincourt health and demographic surveillance site, South Africa. Dev. Policy Rev. 2012; under review.

27. FAO. The Nutrition Transition and Obesity; FAO: New York, NY, USA, 2011. Available online: http://www.fao.org/FOCUS/E/obesity/obes2.htm (accessed on 30 October 2011).

28. Mittal, A. The 2008 Food Price Crisis: Rethinking Food Security Policies. In G-24 Discussion Paper Series No 56, June 2009; UNCTAD: Geneva, Switzerland, 2009.

29. Larson, T. Why there will be no chain supermarkets in poor inner-city neighbourhoods. Calif. Polit. Policy 2003, 7, 22-45.

30. Weatherspoon, D.; Reardon, T. Supermarkets in Africa: Implications for Agrifood systems and the rural poor. Dev. Policy Rev. 2003, 2, 1-17.

31. Crush, J.; Frayne, B. Pathways to Insecurity: Food Supply and Access in Southern African Cities; African Food Security Urban Network(AFSUN), Urban Food Security Series 3; Unity Press: Cape Town, South Africa, 2010.

32. Reardon, T.; Timmer, C.; Berdegué, J. Supermarket expansion in Latin America and Asia: Implications for food marketing systems. In New Directions in Global Food Markets; Economic Research Service, USDA: Washington, DC, USA, 2007.

33. Reardon, T.; Barrett, C.; Berdegué, J.; Swinnen, J. Agrifood industry transformation and small farmers in developing countries. World Dev. 2009, 37, 1717-1727.

34. Pereira, L.; Ruysenaar, S. Moving from Traditional Government to New Adaptive governance: The changing face of food security responses in South Africa. Food Secur. 2012, 4, 41-58.

35. Arda, M. Food Retailing, Supermarkets, and Food Security: Highlights from Latin America. In Food Security; Oxford University Press: New York, NY, USA, 2007.

36. EDD. The new growth path: The framework. Technical report; Economic Development Department: Pretoria, South Africa, 2010.

37. Deloitte. Global Powers of Retailing Report; Deloitte: New York, NY, USA, 2009. Available online: http://www.deloitte.com/view/en_gx/global/e29655baf1001210VgnVCM100000ba42f00a RCRD.htm (accessed on 12 January 2012).

38. Louw, A.; Vermeulen, H.; Kirsten, J.; Madevu, H. Securing small farmer participation in supermarket supply chains in South Africa. Dev. S. Afr. 2006, 24, 539-551.

39. Malan, D. Corporate citizens, colonialists, tourists or activists? Ethical challenges facing South African corporations in Africa. J. Corp. Citizensh. 2005, 18, 49-60.

40. Swilling, M.; Simone, A.; Khan, F. "My Soul I Can See": The Limits of Governing African Cities in a Context of Globalisation and Complexity. In Democratising Local Government. The South African Experiment; University of Cape Town Press: Cape Town, South Africa, 2002; pp. 305-327.

41. Roussouw, G.J.; van der Watt, A.; Malan, D. Corporate governance in South Africa. J. Bus. Ethics 2002, 37, 289-302.

42. Hamann, R.; Kapelus, P. Local governance as a complex system: Lessons from mining in South Africa, Mali and Zambia. J. Corp. Citizensh. 2005, 18, 61-73.

43. Meijerink, G.; Danse, M. Riding the Wave, High Prices, Big Business? The Role of Multinationals in the International Grain Market; LEI Wageningen: The Hague, The Netherlands, 2009. 
44. Ingram, J. What are the implications between the food security and planetary boundaries? Lecture, 27 January 2012.

45. Vogel, C. Business and climate change: Initial explorations in South Africa. Clim. Dev. 2009, $1,82-87$.

46. Jones, P.; Thornton, P. Potential impacts of climate change on maize production in Africa and Latin America in 2055. Glob. Environ. Chang. 2003, 13, 51-59.

47. Easterling, W.E.; Aggarwal, P.; Batima, P.; Brander, K.M.; Erda, L.; Howden, M.; Kirilenko, A.; Morton, J.; Soussana, J.F.; Schmidhuber, J.; et al. Food, Fibre and Forest Products. Climate Change 2007: Impacts, Adaptation and Vulnerability. Contribution of Working Group II to the Fourth Assessment Report of the Intergovernmental Panel on Climate Change. In Contribution of Working Group II to the Fourth Assessment Report of the Intergovernmental Panel on Climate Change; Parry, M., Canziani, O., Palutikof, J., van der Linden, P., Hanson, C., Eds.; Cambridge University Press: Cambridge, UK, 2007; pp. 273-313.

48. Schlenker, W.; Lobell, D. Robust negative impacts of climate change on African agriculture. Environ. Res. Lett. 2010, 5, 1-8.

49. Lobell, D.; Burke, M.; Tebaldi, C.; Mastrandea, M.; Falcon, W.; Naylor, R. Prioritising climate change adaptation needs for food security in 2030. Science 2008, 319, 607-610.

50. Taylor, J. Overview: The importance of sorghum in Africa. In Proceedings of AFRIPRO Workshop on the Proteins of Sorghum And Millets: Enhancing Nutritional and Functional Properties for Africa, Pretoria, South Africa, 9 September 2003.

51. Schilpzand, R.; Liverman, D.; Tecklin, D.; Gordon, R.; Pereira, L.; Saxl, M. Governance beyond the State. In Food Security and Global Environmental Change; Ingram, J., Ericksen, P., Liverman, D., Eds.; Earthscan: London, UK, 2010; pp. 272-300.

52. Tiger Brands. Headquarters, Johannesburg, South Africa. Personal communication, 2010.

53. Harvey, M. Markets, Supermarkets and the Macro-Social Shaping of Demand: An Instituted Economic Process Approach. In Innovation by Demand: An Interdisciplinary Approach to the Study of Demand and Its Role in Innovation; McMeekin, A., Green, K.,Tomlinson, M., Walsh, V., Eds.; Manchester University Press: Manchester, UK, 2002; pp. 187-208.

54. Tiger Brands. Headquarters, Johannesburg, South Africa. Personal Communication, September 2009.

55. South African Audience Research Foundation. Living Standards Measure. Available online: http://www.saarf.co.za/LSM/lsms.asp (accessed on 7 March 2013).

56. Pick 'n Pay. Bedfordview, Johannesburg, South Africa. Personal communication, December 2009.

57. Woolworths. Headquarters, Cape Town, South Africa. Personal communication, August 2010.

58. Pick 'n Pay. Headquarters, Cape Town, South Africa. Personal communication, January 2010.

59. Emerge Conference. Saïd Business School, Oxford, UK, 29-30 October 2011.

60. Pereira, L.; Fontoura, Y.; Fontoura, C. Strategic Corporate Shifts towards Adaptive Food Governance under Environmental Change. In Proceedings of the GBATA Annual Conference, Kruger National Park, South Africa, 5-9 July 2010.

61. Homer-Dixon, T. The Upside of Down; Island Press: Washington, DC, USA, 2006.

62. Schumpeter, J. Capitalism, Socialism and Democracy; Allen and Unwin: London, UK, 1943. 
63. Michelson, H.; Reardon, T.; Perez, F. Small farmers and big detail: Trade-offs of supplying supermarkets in Nicaragua. World Dev. 2012, 40, 342-354.

(C) 2013 by the author; licensee MDPI, Basel, Switzerland. This article is an open access article distributed under the terms and conditions of the Creative Commons Attribution license (http://creativecommons.org/licenses/by/3.0/). 